\title{
The use of cell-free fetal DNA in maternal plasma for noninvasive prenatal linkage analysis in beta globin gene cluster
}

\author{
Khordadpoor-Deilamani $\mathrm{F}^{1,3}$, Akbari $\mathrm{MT}^{2,3}$ \\ Department of Medical Genetics, Faculty of Medical Sciences, Tarbiat Modares University, Tehran, Iran. \\ mtakbari@modares.ac.ir
}

\begin{abstract}
OBJECTIVES: To use the PCR-RFLP-based linkage analysis for non-invasive prenatal diagnosis of $\beta$-thalassemia. BACKGROUNDS: Thalassemia is a prevalent genetic disorder occurring throughout the world. Cell-free fetal DNA (cffDNA) in the maternal plasma during pregnancy has been used to develop non-invasive prenatal screening and diagnostic tests.

METHODS: PCR-RFLP for six SNPs in the $\beta$-globin gene was executed on paternal and maternal DNA as well as DNA extracted from CVS of the fetuses in seven $\beta$-thalassemic families. Based on the results, two families in which the paternal inherited SNPs in specific loci were different from the maternal one were selected and PCR-RFLP was performed on cffDNA extracted from the maternal plasma.

RESULTS: Paternal SNPs in cffDNA were distinguished and the inheritance of paternally normal or mutant $\beta$ globin allele was predicted by linkage analysis.

CONCLUSION: The use of PCR-RFLP on cffDNA as a simple and inexpensive method was capable to provide similar results achieved by studying CVS of the fetuses. However, there is a limiting factor in this approach, namely that there is the little amount of cffDNA in maternal plasma. The PCR yield was improved either by adding BSA to PCR reaction or increasing the PCR cycles (Tab. 2, Fig. 2, Ref. 18). Text in PDF www.elis.sk. KEY WORDS: cffDNA, $\beta$-thalassemia, noninvasive prenatal diagnosis.
\end{abstract}

\section{Introduction}

$\beta$-thalassemiais one of the commonest autosomal recessive diseases with a high frequency in population of the Mediterranean area, Middle East, Indian subcontinent, Far East, Tropical Africa, and the Caribbean (1). The $\beta$-globin gene cluster is located on human chromosome $11 \mathrm{p} 15.5$ including the genes arranged in the order 5 '- $\varepsilon-\mathrm{G} \gamma-\mathrm{A} \gamma-\psi \beta-\delta-\beta-3$ '. The human $\beta$-globin gene complex spans a region of $70 \mathrm{~kb}$ and contains over 20 SNPs mostly detectable by RFLP analysis (2).

Prenatal diagnosis of fetal genetic diseases based on the invasive methods such as chorionic villus or amniotic fluid sampling increases the risk of fetal loss (3). The discovery of cffDNA in maternal plasma has ushered an era for noninvasive prenatal diagnosis $(4,5)$.

The concentration of fetal DNA in the maternal plasma is low and constitutes $10-20 \%$ of total DNA in maternal plasma $(4,6)$. Also

${ }^{1}$ Department of Biology, Science and Research Branch, Islamic Azad University, Tehran, Iran, ${ }^{2}$ Department of Medical Genetics, Faculty of Medical Sciences, Tarbiat Modares University, Jalal Al-Ahmad Express Way, Nasr bridge, Tehran, Iran, and ${ }^{3}$ Tehran Medical Genetics Laboratory, No. 251, Taleghani Street, Tehran, Iran

Address for correspondence: M.T. Akbari, MD, Department of Medical Genetics, Faculty of Medical Sciences, Tarbiat Modares University, P.O. Box 14115-331, Tehran, Iran.

Acknowledgement: The authors thank the $\beta$-thalassemic families for their collaboration. The personnel of Tehran Medical Genetics Laboratory are acknowledged for their help and support. This project was financially supported by Tehran Medical Genetics Laboratory; Grant Number 910010. the maternal background DNA coexists with the cffDNA in the maternal plasma so it is difficult to distinguish between the maternally inherited fetal alleles and background alleles of the mother $(3,7,8)$. To tackle these issues the researchers have focused on paternally inherited alleles (9), removing the maternally inherited alleles based on differential DNA methylation between fetus and mother (10), using gel electrophoresis to enrich the fetal DNA $(8,11)$ and applying digital PCR (12) or next generation sequencing (NGS) (12, 13) for assessment of the inheritance of the maternal mutant allele.

There are some reports of the analysis of mutations in $\beta$-globin gene with the purpose of non-invasive prenatal diagnosis using real-time PCR (14), NGS (15), arrayed primer extension (APEX) $(16,17)$, allele-specific polymerase chain reaction (AS-PCR) (17). Also the use of PCR-RFLP in cffDNA for noninvasive prenatal diagnosis of Achondroplasia is reported (18).

Here we investigated the feasibility of prenatal exclusion of $\beta$-thalassemia major through the analysis of cffDNA. We used PCRRFLP to track the transmission of paternal SNPs in cffDNA in families where the maternal SNP is different from the fetus's paternally inherited one. This enables us to differentiate between paternally mutant and normal alleles received by the fetus through linkage analysis.

\section{Materials and methods}

\section{Patients}

Seven $\beta$-thalassemic families undergoing prenatal diagnosis were initially screened to obtain suitable families enabling us to 
Tab. 1. Six primer pairs designed for analysis of $\beta$-globin gene cluster RFLPs. The product size was determined based on GenBank reference sequence U01317.1.

\begin{tabular}{|c|c|c|c|c|}
\hline RFLP Site & Primers & Product size $(\mathrm{bp})$ & Absence of site (bp) & Presence of site (bp) \\
\hline \multirow[t]{2}{*}{$\overline{\beta-H i n f ~ I ~}$} & TTGTTTTAGCTGTCCTCATGAATG & 156 & 156 & 67 \\
\hline & CAGGCGAGGAGAAACCATCT & & & 89 \\
\hline \multirow[t]{2}{*}{$3^{6} \psi \beta /$ HindII } & TCGTAGTATTTATAGGTCATGAGGTTC & 162 & 162 & 59 \\
\hline & CTTGATGGACCCTAACTGATATAACT & & & 103 \\
\hline \multirow[t]{2}{*}{$\overline{5^{6} \psi \beta / \text { HindII }}$} & TCCTATCCATTACTGTTCCTTGAA & 170 & 170 & 104 \\
\hline & AGCTTCAATATGACTGGCAGC & & & 66 \\
\hline \multirow[t]{2}{*}{$\varepsilon /$ Hind II } & AAGAGCTAGAACTGGGTGAGATTC & 160 & 160 & 68 \\
\hline & AGAAAGACTCATATAAAGGAGCAAATC & & & 92 \\
\hline \multirow[t]{2}{*}{$\overline{\beta-A v a ~ I I ~(E c o 47 I) ~}$} & GCTCACCTGGACAACCTCAAG & 160 & 160 & 99 \\
\hline & TCCCCTTCCTATGACATGAACTT & & & 61 \\
\hline \multirow[t]{2}{*}{$\overline{\beta-R s a I}$} & ACATAATTTATTAGCATGCATGAGCA & 169 & 169 & 79 \\
\hline & TACCTCGGTTCTAAGCATATCTTCT & & & 90 \\
\hline
\end{tabular}

Tab. 2. PCR-RFLP results.

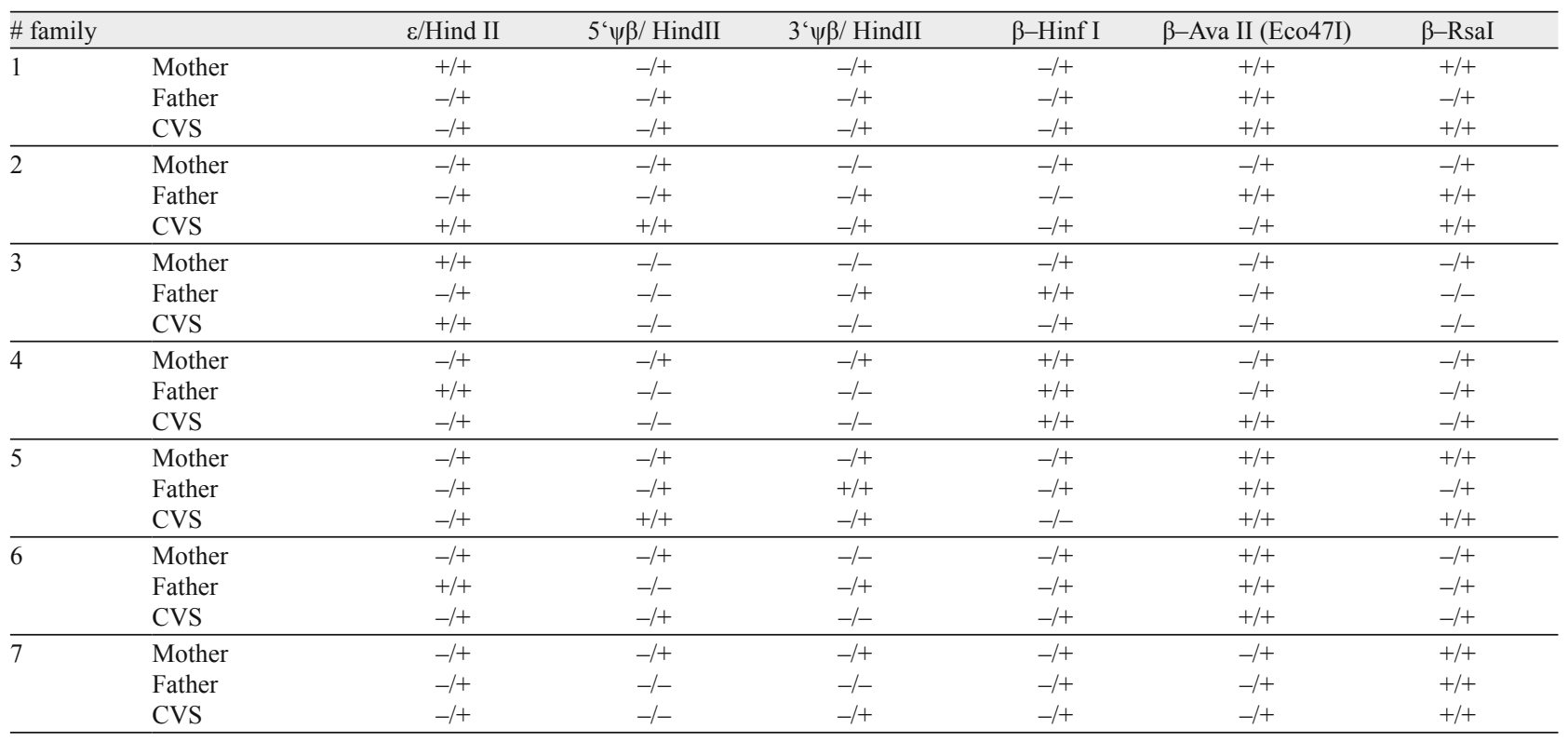

study the transmission of normal or mutant allele by linkage analysis. These couples gave their written consent after being briefed about the project. Two families met our criteria, in the sense that the mother was homozygous for a specific locus and the fetus inherited a different SNP from its father.

\section{Genomic DNA extraction}

DNA was extracted from $3 \mathrm{ml}$ of peripheral blood from each couple by salting-out method.

\section{Plasma separation}

Additionally, $10 \mathrm{ml}$ of maternal blood was collected into EDTA tubes ( $5 \mathrm{ml}$ in each tube). After centrifuging the whole blood at $1600 \mathrm{~g}$ for 10 minutes, the supernatant (plasma) was divided into several $1.5 \mathrm{ml}$ micro tubes. For removing the residual cells, the second centrifugation was performed at $16,000 \mathrm{~g}$ for 10 minutes at $4{ }^{\circ} \mathrm{C}$ and the supernatant was transferred to fresh tubes.

\section{cffDNA extraction}

QIAamp DNA blood Maxi kit was used to extract the total cffDNA from maternal plasma using the manufacturer's protocol.

At the same time DNA was extracted from CVS using phenol chloroform method.

\section{Primer design}

The primer pairs were designed for six RFLP sites on $\beta$-globin gene cluster (Hinf I, RsaI, 3' $\psi \beta /$ HindII, 5' $\psi \beta /$ HindII, $\varepsilon /$ Hind II, Ava II (Eco47I)) by using Gene Runner software. Due to the small size of cffDNA in maternal plasma, the sizes of PCR products were designed to be less than $200 \mathrm{bp}$ (Tab. 1).

\section{PCR-RFLP}

PCR-RFLP was performed on paternal, and maternal DNA extracted from CVS in seven families (Tab. 2). PCR conditions were as follows: $5 \mathrm{~min}$ at $95{ }^{\circ} \mathrm{C}, 30$ cycles per $30 \mathrm{~s}$ at $94{ }^{\circ} \mathrm{C}, 30$ 


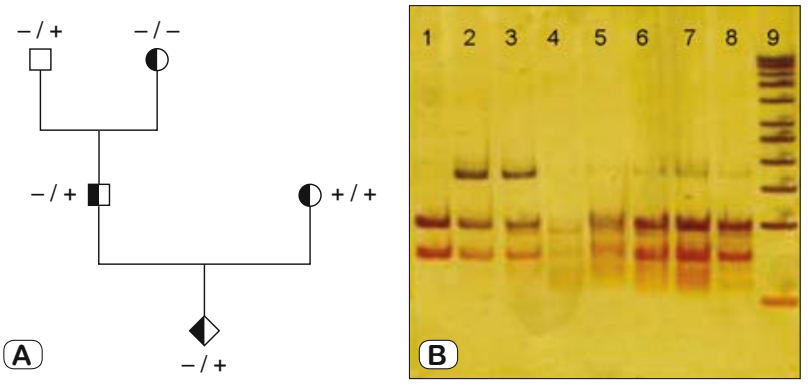

Fig. 1. Family 1. A: The pedigree (the phenotypes were determined by hematologic tests, i.e. CBC and Hb electrophoresis); B: RFLP pattern in locus $\varepsilon /$ Hinc II. 1: mother (+/+), 2: father $(-/+), 3$ : CVS $(-/+), 4$ : cffDNA (after 33 amplification cycles), 5: cffDNA (after 35 amplification cycles), 6 and 8: cffDNA(after 37 amplification cycles), 7: cffDNA (after 40 amplification cycles), 9: 50 bp DNA ladder.

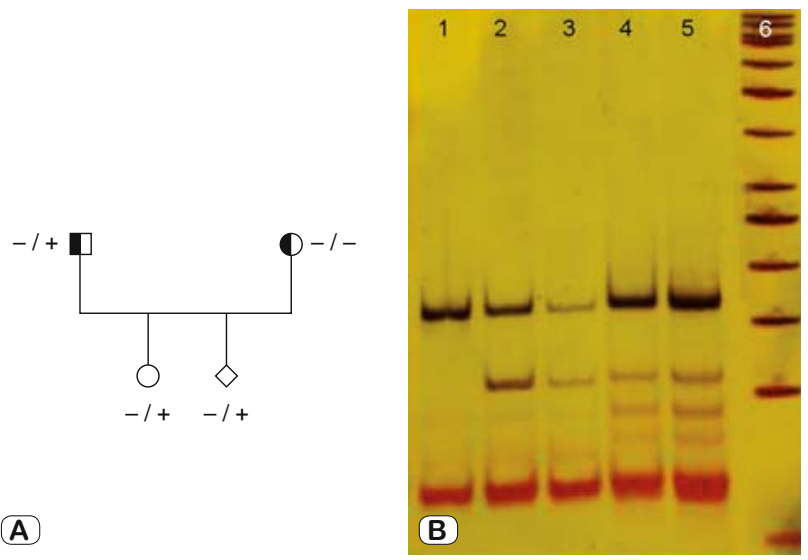

Fig. 2. Family 2. A: The pedigree (the phenotypes were determined by hematologic tests, i.e. CBC and $\mathrm{Hb}$ electrophoresis) and RFLP pattern in locus 3' $\psi \beta$; B: result of PCR-RFLP for Locus 3' $\psi \beta$;. 1: mother (- $/-)$, 2: father $(-/+), 3$ : CVS $(-/+), 4$ and 5: cffDNA (after 40 amplification cycles), 6: 50 bp DNA ladder.

s at $63{ }^{\circ} \mathrm{C}$ and $30 \mathrm{~s}$ at $72{ }^{\circ} \mathrm{C}$, followed by incubation at $72{ }^{\circ} \mathrm{C}$ for $10 \mathrm{~min}$. Digestion was carried out with the related restriction enzyme at each site.

After obtaining the RFLP patterns in each locus, PCR-RFLP was executed on cffDNAs in families whose fetuses had distinguishable RFLP patterns in comparison with their mothers. In other words, the fetal DNA was $-/+$ and its mother was homozygous $(-/-$ or $+/+)$ for a specific locus (locus $\varepsilon /$ Hind II in family 1 and locus 3 ' $\psi \beta /$ /Hind II in family 2 ).

In order to improve the intensity of bands on the polyacrylamide gel, we increased the number of amplification cycles up to 40 and/or used BSA (Bovine Serum Albumin) while keeping the amplification cycles at 30 .

\section{Results}

Both increasing the PCR cycles and using BSA enhanced the detection of the paternal alleles in DNA extracted from plasma. In the following, the pedigrees and the images of gel electrophoresis of PCR-RFLP products in two families are presented. In Figure 1, paternal thalassemia allele which is linked to $(-)$ chromosome has been transmitted to the fetus as identified by testing CVS DNA. This has been similarly detected by assaying cffDNA. Therefore, the fetus has received a mutant paternal allele. In Figure 2, the normal allele is linked to $(+)$ chromosome. This allele was detected by both CVS and cffDNA. Therefore, the fetus has received a normal paternal allele.

\section{Discussion}

Due to the significant risk of fetal miscarriage associated with invasive prenatal diagnosis, there has been an intensive search for the development of noninvasive prenatal diagnostic tests.

In this study, we aimed at demonstrating the feasibility of the use of PCR-RFLP for cffDNA-based noninvasive prenatal diagnosis. Nevertheless, due to low concentration of cffDNA in maternal plasma, the paternal allele may not be visible with few rounds of PCR cycles. So we increased the number of cycles up to 40 . The more PCR cycles, the more intense bands on polyacrylamide gel were achieved. But since increasing the number of PCR cycles may result in non-specific amplification, we also used BSA as a component of PCR reaction which resulted in increasing the PCR yields so that the paternal alleles were distinguishable even after 30 PCR cycles.

Since the SNPs used in our study are linked to the $\beta$-globin genes, we can investigate the inheritance of the paternally normal or mutant allele in the fetus using linkage analysis.

The limitation of this approach is that it cannot determine whether a fetus which is positive for a paternal mutation has $\beta$-thalassemia major or $\beta$-thalassemia minor. In such cases more investigation is needed to determine the fate of maternally inherited allele too in order to provide proper diagnosis for the fetus in question. So this method can be used as an initial noninvasive screening tool.

In family 1, the negative RFLP allele was linked to the mutant $\beta$-globin gene. Since the fetus has inherited this negative allele, it has inherited the paternally mutant $\beta$-globin gene too which is similar to the result obtained by CVS of the same fetus.

In family 2, the positive RFLP allele is linked to the normal $\beta$-globin gene. So the fetus has inherited the paternally normal $\beta$-globin gene.

In conclusion, we have been able to determine the transmission pattern of paternal SNPs to the fetus using cffDNA. This paves the way to assess the status of the fetus with regards to its paternal alleles provided there are informative SNPs in the family. Since the chance of inheriting the normal paternal allele by the fetus is $50 \%$, one can predict that a half of the fetuses are not affected with major $\beta$-thalassemia. So through the exclusion of inheritance of the paternal mutation, the need for invasive prenatal diagnosis procedures could be eliminated in a half of these pregnancies.

\section{References}

1. Rosatelli MC, Saba L. Prenatal Diagnosis of beta-Thalassemias and Hemoglobinopathies. Mediterr J Hematol Infect Dis 2009; 1 (1): e2009011. 
2. Falchi A, Giovannoni L, Vacca L, Latini V, Vona G, Varesi L. betaglobin gene cluster haplotypes associated with beta-thalassemia on Corsica island. Am J Hematol 2005; 78 (1): 27-32.

3. Lun FM, Tsui NB, Chan KC, Leung TY, Lau TK, Charoenkwan P, Chow KC, Lo WY, Wanapirak C, Sanguansermsri T et al. Noninvasive prenatal diagnosis of monogenic diseases by digital size selection and relative mutation dosage on DNA in maternal plasma. Proc Natl Acad Sci USA 2008; 105 (50): 19920-19925.

4. Lo YM, Chiu RW. Noninvasive prenatal diagnosis of fetal chromosomal aneuploidies by maternal plasma nucleic acid analysis. Clin Chem 2008; 54 (3): 461-466.

5. Go AT, van Vugt JM, Oudejans CB. Non-invasive aneuploidy detection using free fetal DNA and RNA in maternal plasma: recent progress and future possibilities. Hum Reprod Update 2011; 17 (3): 372-382.

6. Tsui NB, Kadir RA, Chan KC, Chi C, Mellars G, Tuddenham EG, Leung TY, Lau TK, Chiu RW, Lo YM. Noninvasive prenatal diagnosis of hemophilia by microfluidics digital PCR analysis of maternal plasma DNA. Blood 2011; 117 (13): 3684-3691.

7. Li GH, Rong KB, Luo YF, Chen D, Gong CP, Wu J, Di YW, Ge YF. (Prenatal diagnosis of beta-thalassaemia using cell-free fetal DNA in maternal plasma). Nan Fang Yi Ke Da Xue Xue Bao 2011; 31 (8): 1437-1439.

8. Li Y, Zimmermann B, Rusterholz C, Kang A, Holzgreve W, Hahn S. Size separation of circulatory DNA in maternal plasma permits ready detection of fetal DNA polymorphisms. Clin Chem 2004; 50 (6): 1002-1011.

9. Gonzalez-Gonzalez MC, Trujillo MJ, Rodriguez de Alba M, Garcia-Hoyos M, Lorda-Sanchez I, Diaz-Recasens J, Ayuso C, Ramos C. Huntington disease-unaffected fetus diagnosed from maternal plasma using QF-PCR. Prenat Diagn 2003; 23 (3): 232-234.

10. Poon LL, Leung TN, Lau TK, Chow KC, Lo YM. Differential DNA methylation between fetus and mother as a strategy for detecting fetal DNA in maternal plasma. Clin Chem 2002; 48 (1): 35-41.
11. Li Y, Di Naro E, Vitucci A, Zimmermann B, Holzgreve W, Hahn S. Detection of paternally inherited fetal point mutations for beta-thalassemia using size-fractionated cell-free DNA in maternal plasma. JAMA 2005; 293 (7): 843-849.

12. Lazar L, Nagy GR, Rigo J Jr, Nagy B. (Cell-free nucleic acid-based non-invasive prenatal diagnosis of fetal aneuploidies). Orv Hetil 2012; 153 (43): 1687-1691.

13. Nepomnyashchaya YN, Artemov AV, Roumiantsev SA, Roumyantsev AG, Zhavoronkov A. Non-invasive prenatal diagnostics of aneuploidy using next-generation DNA sequencing technologies, and clinical considerations. Clin Chem Lab Med 2013; 51 (6): 1141-1154.

14. Chiu RW, Lau TK, Leung TN, Chow KC, Chui DH, Lo YM. Prenatal exclusion of beta thalassaemia major by examination of maternal plasma. Lancet 2002; 360 (9338): 998-1000.

15. Papasavva T, van Ijcken WF, Kockx CE, van den Hout MC, Kountouris P, Kythreotis L, Kalogirou E, Grosveld FG, Kleanthous M. Next generation sequencing of SNPs for non-invasive prenatal diagnosis: challenges and feasibility as illustrated by an application to beta-thalassaemia. European journal of human genetics: EJHG 2013; 21 (12): 1403-1410.

16. Papasavva T, Kalikas I, Kyrri A, Kleanthous M. Arrayed primer extension for the noninvasive prenatal diagnosis of beta-thalassemia based on detection of single nucleotide polymorphisms. Ann NY Acad Sci 2008; 1137: 302-308.

17. Papasavva T, Kalakoutis G, Kalikas I, Neokli E, Papacharalambous S, Kyrri A, Kleanthous M. Noninvasive prenatal diagnostic assay for the detection of beta-thalassemia. Ann NY Acad Sci 2006; 1075: 148-153.

18. Saito H, Sekizawa A, Morimoto T, Suzuki M, Yanaihara T. Prenatal DNA diagnosis of a single-gene disorder from maternal plasma. Lancet 2000; 356 (9236): 1170. 